\title{
Simultaneous Dorsal Dislocation of the Proximal and Distal Interphalangeal Joints in the Middle Finger: A Case Report
}

\author{
Mohamed Ali Sbai, ${ }^{1,}$ Haythem Rejeb, ${ }^{1}$ Mayssa El Mchirgui, ${ }^{1}$ Wafa Gharbi, ${ }^{1}$ Chtai Mohamed Sadok, ${ }^{1}$ \\ Souissi Mohamed, ${ }^{1}$ Jerbi Slim, ${ }^{1}$ Adel Khorbi, ${ }^{1}$ and Riadh Maalla ${ }^{2}$ \\ ${ }^{1}$ Orthopedics and Trauma Department, Maamouri Hospital, Nabeul, Tunisia \\ ${ }^{2}$ Plastic Surgery Department, Rabta Hospital Tunis, Tunisia \\ "Corresponding author: Mohamed Ali Sbai, Orthopedics and Trauma Department, Maamouri Hospital, Nabeul, Tunisia. Tel: +216-72100500, E-mail: mohamedali.sbai@rns.tn
}

Received 2017 January 09; Revised 2017 April 28; Accepted 2017 July 06.

\begin{abstract}
Introduction: Dorsal dislocation of a proximal or distal interphalangeal joint is a common clinical problem. However, simultaneous dislocation of both joints in the same digit is rare.

Case Presentation: A 32-year-old male injured his left hand third finger while biking. Examination revealed a stepladder deformity. Neurovascular examination was normal. Radiographs revealed dorsal dislocation of both the proximal and distal interphalangeal joints. The finger was reduced easily by longitudinal manual traction under the digital block. The finger was splinted in the intrinsic plus position for 3 weeks accompanied with active range of motion. After 6 months, the patient returned to normal sporting activity without limitation of motion.

Conclusions: In case of simultaneous dorsal dislocation of a proximal and distal interphalangeal joint, closed reduction is the treatment of choice and it could result in good and normal range of motion.
\end{abstract}

Keywords: Proximal Interphalangeal Joint, Distal Interphalangeal Joint, Dislocation

\section{Introduction}

Simultaneous dislocation of both interphalangeal joints in the same digit is rare (1). Closed reduction and immobilization is often undertaken (2). The authors describe the presentation and management of a double interphalangeal joint dislocation alongside with review of the literature.

\section{Case Report}

The ethic committee of the research institution has approved the study and the patient gave written consent to report the case. A 32-year-old right-handed male patient injured himself while biking by falling on his left hand's third finger. On examination, the finger was markedly deformed with swelling. Neurovascular examination was normal. The X-ray revealed a dorsal dislocation in the third finger proximal and distal interphalangeal joints (Figure $1 \mathrm{~A}$ and $1 \mathrm{~B})$. Accompanying avulsion or shaft fracture was not observed. Under digital block, a closed reduction by traction was performed. Following reduction, it was observed during examination that the joints were stable and anteroposterior and lateral radiographs showed a small avulsion of volar base of the second phalanx (Figure $2 \mathrm{~A}$ and $2 \mathrm{~B})$. Splint was applied in the intrinsic plus position of the finger for 3 weeks and the patient was encouraged for active early range of motion. Within 6 months after the reduction, the patient returned to normal sporting activity without limitation of motion outside a tumefaction at the level of the proximal interphalangeal joint (Figure 3).

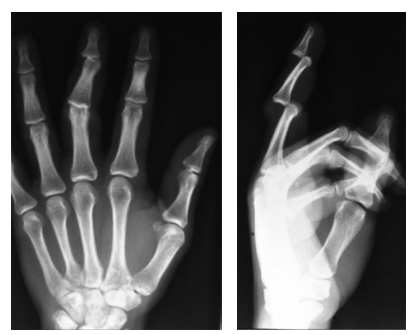

Figure 1. Before Reduction (A) Anteroposterior and (B) Lateral X-Ray.

\section{Discussion}

Double interphalangeal joint dislocation in the same finger is a rare injury that was first defined by Bartels in 1874 (3). The most prevalent cause of injury in the literature was a sport accident, usually in athletes during ball games, such as volleyball and baseball $(3,4)$. 


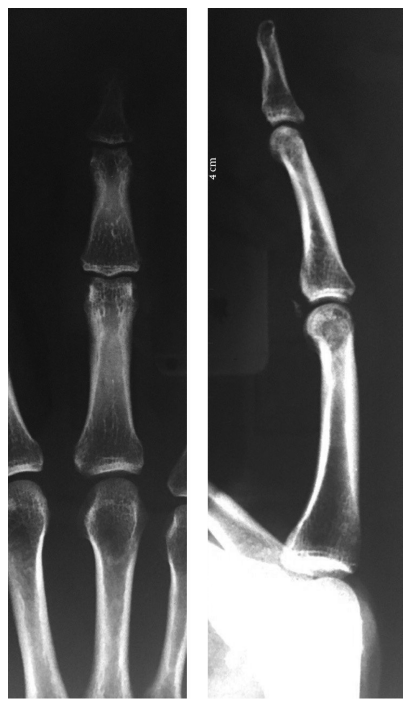

Figure 2. After Reduction (A) Anteroposterior and (B) Lateral X-Ray of the Affected Finger

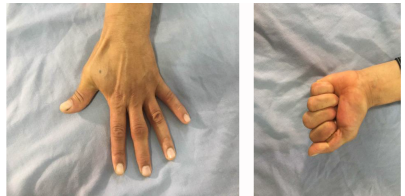

Figure 3. Clinical Aspects and Range of Motion of the Affected Finger After Six Months Post Reduction

The common mechanism of injury is traumatic hyperextension as it is in the current case. The trauma must be strong enough to enhance rupture of the volar capsule allowing dorsal dislocation of the distal interphalangeal joint. The force is then directed to the middle phalange causing similar dislocation of the proximal interphalangeal joint $(5,6)$. Typically, the hyperextension force is dissipated by the distal dislocation, yet if not, then a proximal dislocation may occur.

In the current case accompanying avulsion or shaft fracture was not observed at the first pre-reduction radiographs. However, in the literature it has been specified that bone avulsion fractures and soft tissue interposition (especially volar plate) might be present $(7,8)$. This was true in the current case, in which the $\mathrm{X}$ rays after reduction revealed a small bony avulsion of the volar base of the second phalanx (Figure 2).

It has been stated that the right hand is the most commonly affected. The finger most often injured was the little finger followed by the ring finger, middle finger and the index finger (4).
Closed reduction by longitudinal traction under local anesthesia is the treatment of choice if there is no soft tissue interposition that prohibits the procedure. However, it is always mandatory to test the articulation stability after any reduction attempt (1).

Surgery is required only in cases of neglected injuries, open dislocations, volar plate or ligamentous injuries preventing closed reduction and associated fractures or flexor tendon injuries (5).

Splint duration has been specified to vary between 2 and 4 weeks (4). However, immobilization of fingers may cause joint stiffness (2). Therefore, finger motion exercise should start as early as possible to prevent joint contracture and lead to good functional result.

\subsection{Conclusions}

Simultaneous dislocation of both joints in a single digit is rare. In simple cases, closed reduction is generally sufficient. An early reduction followed by splinting and early range of motion usually lead to good functional result.

\section{Footnote}

Authors' Contribution: All authors were involved in the diagnosis, treatment, and follow up of the patient and drafting and revision of the manuscript.

\section{References}

1. Sbiyaa M, Hamdi O, Habi S, Maatougui K, Boutayeb F. Phalange flottante du cinquième doigt, à propos d'un cas. Journal de Traumatologie du Sport. 2016;33(1):31-3. doi: 10.1016/j.jts.2015.12.001.

2. Seki Y. Simultaneous double dislocation of the interphalangeal joint of the same finger: a report of two cases. Pan Afr Med J. 2014;19:400. doi: 10.11604/pamj.2014.19.400.5933. [PubMed: 25995796].

3. Bartels M. Traumatische luxationen. Arch Klin Chir. 1974;16:645-6.

4. Uysal MA, Akcay S, Ozturk K. Simultaneous double interphalangeal joints dislocation in a finger in a teenager. $J$ Clin Orthop Trauma. 2014;5(2):107-9. doi:10.1016/j.jcot.2014.05.002. [PubMed: 25983481].

5. Nusem I, Loch A. Simultaneous double interphalangeal joints dislocation in a finger in a teenager. Malays Orthop J. 2012;6(1):46-8. doi: 10.5704/MOJ.1203.002. [PubMed: 25279043].

6. Curran AJ, McKiernan MV, McCann J. Double interphalangeal joint dislocation in a little finger. Injury. 1993;24(2):138.

7. Hutchison JD, Hooper G, Robb JE. Double dislocations of digits. J Hand Surg Br. 1991;16(1):114-5. [PubMed: 2007802].

8. Inoue G, Kino Y, Kondo K. Simultaneous dorsal dislocation of both interphalangeal joints in a finger. A J Sports Med. 1993;21(2):323-5. 